\title{
Safety and efficacy of doxycycline in the treatment of rosacea
}

This article was published in the following Dove Press journal:

Clinical, Cosmetic and Investigational Dermatology

12 August 2009

Number of times this article has been viewed

\author{
Sheila Valentín \\ Adisbeth Morales \\ Jorge L Sánchez \\ Abimael Rivera \\ Department of Dermatology, \\ University of Puerto Rico, School \\ of Medicine, San Juan, Puerto Rico
}

Correspondence: Jorge L Sánchez University of Puerto Rico, School of Medicine, Department of Dermatology, PO Box 365067, San Juan,

Puerto Rico 00936-5067

Tel +787 765-7950

Fax +787 767-0467

Email rcmdermatol@gmail.com
Abstract: Rosacea is a common, chronic, skin condition characterized by recurrent episodes of facial flushing, transient or persistent erythema, papules, pustules, and telangiectasias, in a symmetrical facial distribution. The etiology of rosacea remains unknown and this condition represents a therapeutic challenge because of its chronic nature, progression, potential for disfigurement and psychological impact. Although there is no curative therapy for rosacea, the most widely used systemic agents are oral tetracycline derivatives, including tetracycline, doxycycline, and minocycline. This article reviews the available evidence for the use of doxycycline, a second-generation tetracycline, in the treatment or rosacea.

Keywords: rosacea, doxycyline, tetracyclines

Rosacea is a common, chronic dermatologic condition, whose cause remains unknown. It has a higher prevalence in fair-skinned individuals and most commonly affects individuals between the ages of 30 and 50, women being more affected than men. ${ }^{1,2}$ The diagnosis of rosacea requires the presence of one or more of the following primary features concentrated on the central area of the face: flushing (transient erythema), nontransient erythema, papules and pustules, and telangiectasia. ${ }^{3}$ Rosacea represents a therapeutic challenge because of its chronic nature, progression, potential for disfigurement, and psychological impact.

Tetracycline compounds were the first systemic drugs used in the treatment of rosacea, and have been the mainstay therapeutics for more than 40 years, although it has just recently been approved by the FDA for the treatment of this condition. ${ }^{4,5}$ Doxycycline, a second-generation tetracycline, exhibits superior pharmacokinetic properties and lesser toxicity than first-generation tetracyclines. ${ }^{6}$ They also posses antiangiogenic and antiinflammatory properties that make it a promising therapeutic option in the treatment of rosacea. ${ }^{7}$ This paper reviews the safety and efficacy of doxycycline in the treatment of rosacea with emphasis on those clinical studies that support its use.

\section{Pharmacology of doxycycline Chemistry}

The basic chemical structure of tetracyclines consists of a tetracyclic naphtacene carboxamide ring system. ${ }^{7}$ The structures of tetracycline, doxycycline, and minocycline are shown in Figure 1. Doxycycline differs structurally from the tetracycline molecule in the modifications of substituent at positions 5 and 6 of the ring 
system, which make it more lipid soluble. Minocycline has a dimethylamino substituent at position 7 .

\section{Absorption}

Semi-synthetic second-generation tetracyclines, doxycycline and minocycline, are better absorbed after oral administration than first-generation counterparts due to their higher lipid solubility. ${ }^{8-11}$ Pooled data from studies show that mean absorption of oral doxycyline is close to $95 \%{ }^{8,9,12,13}$ After oral administration, the absorption of doxycycline is rapid, being detectable in blood in as little as 15 minutes. ${ }^{12}$

\section{Distribution, metabolism, and excretion}

Doxycycline is widely distributed in tissues, including the skin, because of its high lipophilicity. ${ }^{8-12,14,15}$ No doxycycline metabolites have been found in blood, urine, or feces. ${ }^{12}$ Doxycycline elimination occurs mainly through the gastrointestinal tract. Renal elimination accounts for 30\% to $40 \%$ of the administered dose. ${ }^{12}$ Doxycycline serum levels are minimally affected in patients with renal insufficiency and require no adjustments in dosage..$^{8-9,16}$

\section{Mechanism of action}

Bacteriostatic effects of tetracyclines are due to inhibition of protein synthesis, by binding to the $30 \mathrm{~S}$ subunit on the bacterial ribosome, where they interfere with the binding of the aminoacyl tRNA to the acceptor site on the mRNA-ribosome complex. $^{14}$

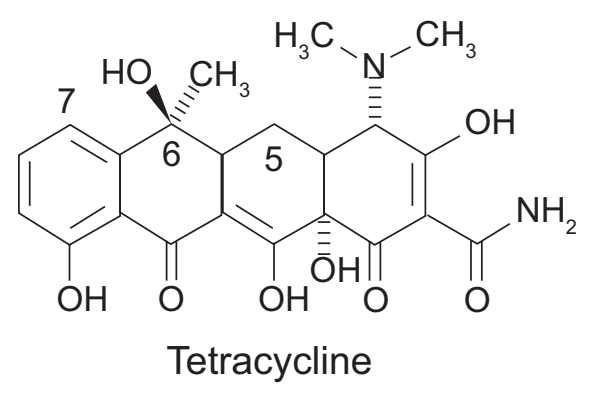

Several studies have shown that tetracylines, including doxycycline, have immunomodulating properties. ${ }^{7,14,17}$ These anti-inflammatory effects have been used to target several pathophysiological mechanisms in rosacea.

Tetracyclines have been shown to inhibit white cell movement during inflammation by interfering with calciumdependent microtubular assembly and to inhibit lymphocytic proliferation by blockage of blast tranformation., ${ }^{77-21}$ Tetracyclines have also been shown to inhibit arachidonic acid (AA) production from cell membrane components, in turn reducing the production of AA-derived proinflammatory mediators. ${ }^{22}$

Tetracyclines can inhibit proteolysis mediated by matrix metalloproteinases (MMPs) which are secreted by activated neutrophils. ${ }^{23,24}$ Studies in vivo and in vitro have demonstrated inhibition of collagenase-3 (MMP-13), collagenase-2 (MMP-8), collagenase-1 (MMP-1), gelatinase A (MMP-2), gelatinase B (MMP-9), and macrophage metalloelastase (MMP-12). ${ }^{25-27}$ Inhibition of gelatinases A and B, which break down the basement membrane of the capillary vessels, promotes integrity of the capillary wall, reduces sensitivity to vasodilatory stimuli, prevents capillary leakage, improves the integrity of connective tissue, and downregulates cytokines (eg, TNF- $\alpha$ and IL-1 $\beta$ ) that assist in erythema and inflammation associated with rosacea. ${ }^{28,29}$ Tetracyclines have also been shown to impair angiogenesis by the inhibition of MMPs, which may affect migration of endothelial cells during angiogenesis. ${ }^{30}$

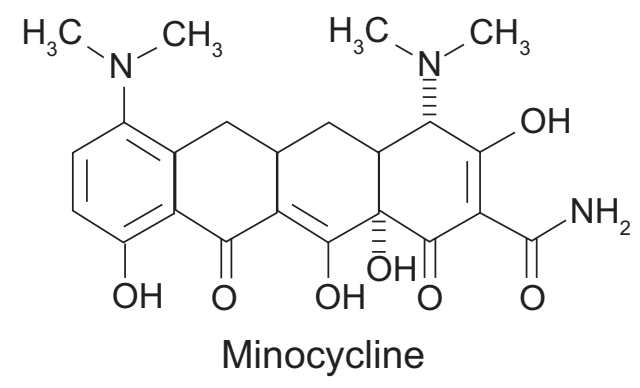

Figure I Chemical structure of tetracyclines. 
Tetracyclines may inhibit nitric oxide (NO) synthetase. This may prove beneficial in rosacea, as excess NO promotes vasodilation and inhibition of extracellular matrix synthesis. $^{31}$

Tetracyclines can affect molecular signaling pathways, such as the inhibition of calcium/calmodulin pathway and inhibition of protein kinase $\mathrm{C}$ activity. This results in decreased transcriptional activity for several MMPs, therefore reducing MMP-mediated extracellular matrix breakdown. Interference with this signaling also reduces vasodilation secondary to the decreased NO production. ${ }^{32-34}$

Several of these anti-inflammatory effects have been proven to occur with doxycycline (Table 1).

\section{Doxycycline in rosacea}

\section{Subantimicrobial dose doxycycline}

The use of doxycycline in rosacea has been proven in several clinical trials either alone or in combination with other therapies (Table 2). Before the introduction of $40 \mathrm{mg}$ doxycycline monohydrate and its FDA approval in 2006 for the treatment of rosacea, there were several reports using subantimicrobial dose doxycycline hyclate $20 \mathrm{mg}$ (SDD). Previous results of a study of doxycycline hyclate $20 \mathrm{mg}$ twice daily for 6 months in the treatment of acne vulgaris had demonstrated a significant decrease in the clinical signs and symptoms without affecting the skin flora. ${ }^{35}$

The first study that reported the efficacy of SDD in the treatment of rosacea was an open-label study that included 50 patients with all stages of rosacea. ${ }^{24}$ Patients were treated with SDD $20 \mathrm{mg}$ twice daily for 8 weeks. After an average of 4 weeks, patients experienced an $80 \%$ to $100 \%$ clearing in inflammatory lesions and a 50\% reduction in erythema. At the end of treatment, there were no reports of gastrointestinal side effects, vaginitis, or photosensitivity.

A multicenter, randomized, double-blind, placebocontrolled, 16-week clinical trial evaluated the use of SDD twice daily versus placebo in 134 patients with moderate rosacea. ${ }^{36}$ The assessment at week 16 relative to baseline showed a reduced lesion count $(P=0.009)$, decreased erythema score $(P=0.082)$, and global severity score $(P=0.034)$ in the study group compared with placebo. In the investigator's global assessment scale (IGA), $13.1 \%$ of the study group patients achieved a score of 0 (clear) versus $1.5 \%$ of those with placebo $(P=0.014)$. Another single-center, randomized, double-blind, placebo-controlled trial evaluated the combined effect of SDD $20 \mathrm{mg}$ and metronidazole $0.75 \%$ topical lotion in the treatment of moderate-to-severe rosacea. ${ }^{37}$ Forty patients were randomized to receive SDD plus metronidaloze twice daily or placebo
Table I Anti-inflammatory effects of doxycycline ${ }^{7}$

Inhibition of mitogen-induced human lymphocytic proliferation by blockage of blast transformation ${ }^{21}$

Inhibition of phospholipase $\mathrm{A}^{22}$

Inhibition of the expression of nitric oxide synthetase ${ }^{33,34}$

Accelerated degradation of nitric oxide synthetase ${ }^{34}$

plus metronidazole twice daily for 12 weeks. SDD or placebo monotherapy continued for 4 weeks after metronidazole was discontinued. Results demonstrated a significant reduction from baseline in the total inflammatory lesion count at week 12 $(P<0.01)$ that was maintained at week 16 , after 4 weeks of SDD as monotherapy $(P<0.01)$. Secondary endpoints of global severity and erythema were also reduced significantly by the combination treatment. There were no between-group differences observed in adverse events and there were no cases of photosensitivity or vaginitis reported.

\section{Anti-inflammatory dose doxycycline}

Anti-inflammatory dose doxycycline (Oracea ${ }^{\circledR}$; Galderma) refers to a specific $40 \mathrm{mg}$ capsule formulation of doxycycline monohydrate containing $30 \mathrm{mg}$ immediate-release and $10 \mathrm{mg}$ delayed-release beads administered once daily and that is devoid of antibiotic activity. ${ }^{31}$ It was approved by the FDA in 2006 and is currently the only doxycyline formulation with FDA approval for the treatment of rosacea. Two phase 3, randomized, multicenter, double-blind, placebo-controlled, parallel-group monotherapy trials evaluated the use of once daily anti-inflammatory dose doxycycline $(n=269)$ or placebo $(n=268)$ for 16 weeks in the treatment of moderate to severe rosacea. ${ }^{31}$ The mean changes from baseline in total inflammatory lesion count in the active treatment groups were -11.8 and -9.5 compared to -5.9 and -4.3 in the placebo arms $(P<0.001)$. This decrease in lesion count was seen as early as 3 weeks, and there was a progressive continued reduction throughout the entire study period. Also, a statistically significant greater reduction in mean total erythema from baseline was observed in the actively treated group compared with placebo-treated subjects in one pivotal study $(P=0.017)$. Anti-inflammatory dose doxycycline once daily was well tolerated. The percentage of patients discontinuing therapy because of adverse events was very low in both trials and was similar in both the active treatment and placebo group. Vaginal candidiasis and photosensitivity were not reported in the actively treated patients.

The efficacy of anti-inflammatory dose doxycycline in combination therapy for rosacea has also been reported. In a randomized, multicenter, double-blind, placebo-controlled, 
Table 2 Studies of doxycycline in rosacea

\begin{tabular}{|c|c|c|c|c|c|}
\hline Study & $\begin{array}{l}\text { No of } \\
\text { subjects }\end{array}$ & $\begin{array}{l}\text { Length of } \\
\text { trial }\end{array}$ & Design & Results & Comments \\
\hline Open-label ${ }^{24}$ & 50 & 8 weeks & $\begin{array}{l}\text { Doxycycline hyclate } 20 \mathrm{mg} \\
\text { twice daily }\end{array}$ & $\begin{array}{l}80 \% \text { to } 100 \% \text { clearance } \\
\text { of inflammatory lesions } \\
\text { and a } 50 \% \text { reduction in } \\
\text { erythema }\end{array}$ & $\begin{array}{l}\text { No adverse events } \\
\text { reported }\end{array}$ \\
\hline $\begin{array}{l}\text { Multicenter, randomized, } \\
\text { double-blind, } \\
\text { placebo-controlled }^{36}\end{array}$ & 134 & 16 weeks & $\begin{array}{l}\text { Doxycycline hyclate } 20 \mathrm{mg} \\
\text { twice daily vs placebo }\end{array}$ & $\begin{array}{l}\text { Reduced lesion count } \\
(P=0.009) \text {, and global } \\
\text { severity score } \\
(P=0.034)\end{array}$ & $\begin{array}{l}\text { No adverse events } \\
\text { reported }\end{array}$ \\
\hline $\begin{array}{l}\text { Single-center, } \\
\text { randomized, } \\
\text { double-blind, } \\
\text { placebo-controlled }^{37}\end{array}$ & 40 & 16 weeks & $\begin{array}{l}\text { Doxycycline hyclate } \\
20 \text { mg twice daily plus } \\
\text { metronidazole } 0.75 \% \\
\text { lotion vs placebo plus } \\
\text { metronidazole } 0.75 \% \text { lotion. } \\
\text { Metronidazole discontinued } \\
\text { in both groups at week } 12\end{array}$ & $\begin{array}{l}\text { Reduced lesion count } \\
(P<0.0 \mathrm{I}) \text { at week I2 } \\
\text { that was maintained at } \\
\text { week I6 after } 4 \text { weeks } \\
\text { of doxycycline as } \\
\text { monotherapy }(P<0.0 \mathrm{I}) \\
\text { and decreased global } \\
\text { severity score }(P=0.046)\end{array}$ & $\begin{array}{l}\text { Gastrointestinal events } \\
\text { more common in the } \\
\text { subantimicrobial-dose } \\
\text { doxycycline/metronidazole } \\
\text { group ( } 5 \text { vs } 2 \text { ). No cases } \\
\text { of photosensitivity or } \\
\text { vaginitis reported }\end{array}$ \\
\hline $\begin{array}{l}\text { Multicenter, randomized } \\
\text { double-blind, } \\
\text { placebo-controlled }^{31}\end{array}$ & 573 & 16 weeks & $\begin{array}{l}\text { Doxycycline } 40 \mathrm{mg} \text { once } \\
\text { daily vs placebo }\end{array}$ & $\begin{array}{l}\text { Reduced lesion count } \\
(P<.00 I) \text {, decreased } \\
\text { erythema score } \\
(P=0.017)\end{array}$ & $\begin{array}{l}\text { Adverse events were } \\
\text { similar in both groups. No } \\
\text { cases of photosensitivity } \\
\text { or vaginitis reported }\end{array}$ \\
\hline $\begin{array}{l}\text { Multicenter, randomized } \\
\text { double-blind, } \\
\text { placebo-controlled }\end{array}$ & 72 & 16 weeks & $\begin{array}{l}\text { Doxycycline } 40 \text { mg plus } \\
\text { metronidazole gel I\% once } \\
\text { daily vs metronidazole } \\
\text { gel I\% and placebo. } \\
\text { Metronidazole discontinued } \\
\text { at week } 12 \text { in both groups }\end{array}$ & $\begin{array}{l}\text { Reduced lesion count at } \\
\text { week } 4(P=0.008) \text { and } \\
\text { at week I } 2(P=0.002) \text {, } \\
\text { decreased global severity } \\
\text { score }(P=0.01) \text { that } \\
\text { was maintained through } \\
\text { weeks } 12 \text { to } 16\end{array}$ & $\begin{array}{l}\text { Improvement receded in } \\
\text { the group that received } \\
\text { only placebo from week } \\
12 \text { to } 16\end{array}$ \\
\hline $\begin{array}{l}\text { Multicenter, randomized, } \\
\text { double-blind, } \\
\text { active-control }^{39}\end{array}$ & 91 & 16 weeks & $\begin{array}{l}\text { Doxycyline } 40 \text { mg plus } \\
\text { metronidazole gel I\% once } \\
\text { daily vs doxycycline } 100 \text { mg } \\
\text { plus metronidazole gel I\% } \\
\text { once daily }\end{array}$ & $\begin{array}{l}\text { Similar mean change } \\
\text { in inflammatory lesion } \\
\text { count }\end{array}$ & $\begin{array}{l}\text { Adverse events reported } \\
\text { in } 26 \text { subjects in the } \\
100 \mathrm{mg} \text { group versus } \\
6 \text { subjects in the } 40 \mathrm{mg} \\
\text { group }\end{array}$ \\
\hline
\end{tabular}

16-week trial, the combined effect of anti-inflammatory dose doxycycline $40 \mathrm{mg}$ and metronidazole gel $1 \%$ once daily $(n=36)$ was compared to placebo capsule and metronidazole gel $1 \%$ once daily $(\mathrm{n}=36)$ in adults with mild to moderate rosacea. ${ }^{38}$ After 12 weeks, metronidazole was discontinued allowing for comparison of anti-inflammatory dose doxycycline and placebo from week 12 to week 16. At both 4 weeks and 12 weeks assessments, the mean inflammatory lesion reduction from baseline was statistically significant in the anti-inflammatory dose doxycycline and metronidazole study $\operatorname{arm}(P=0.008$ week 4 and $P=0.002$ week 12$)$. From weeks 12 through 16, after discontinuation of metronidazole in both study arms, the improvement noted in the first 12 weeks receded in subjects who received only placebo compared with those subjects receiving only anti-inflammatory dose doxycycline. The results of this study indicate that concurrent use of anti-inflammatory dose doxycycline and metronidazole produces a greater magnitude of inflammatory lesion reduction than metronidazole alone.

\section{Anti-inflammatory dose doxycycline compared with conventional dose doxycycline}

When comparing anti-inflammatory dose doxycycline with anti-microbial dose doxycycline, a randomized, multi-center, double-blind, active-control, 16-week trial evaluated the efficacy of anti-inflammatory dose doxycycline (40 mg) and topical metronidazole gel $1 \%$ once daily $(n=44)$ versus conventional dose doxycycline $(100 \mathrm{mg})$ and metronidazole gel $1 \%$ once daily $(n=47)$ in adults with moderate to severe rosacea. ${ }^{39}$ The mean change from baseline to week 16 in inflammatory lesion count was similar in both study groups and at all study visits. The mean change in erythema score from baseline was slightly greater at all time points in the 
$40 \mathrm{mg}$ group. This was statistically significant at week 12 $(P<0.04)$, but not at week 16 . The most frequent adverse events included nausea, headache, influenza, nasopharyngitis, urticaria, diarrhea, esophageal pain, vomiting, abdominal pain, and upper abdominal pain in 32 patients. Of these, 26 subjects were in the $100 \mathrm{mg}$ group and 6 subjects were in the $40 \mathrm{mg}$ group. This study demonstrates that although both anti-inflammatory dose doxycycline (40 mg) and conventional dose doxycycline (100 mg) are effective once-daily treatments for moderate to severe rosacea, a higher incidence of adverse events is associated with the use of the $100 \mathrm{mg}$ dose.

\section{Doxycycline in ocular rosacea}

Several nonplacebo-controlled studies have reported improvement in the signs and symptoms of ocular rosacea when treated with tetracycline or its derivatives. The largest restrospective study report described improvement in $98 \%$ of 113 patients given either tetracycline $250 \mathrm{mg} 4$ times daily or doxycycline $100 \mathrm{mg}$ once daily. ${ }^{40}$ Other prospective studies have demonstrated that between $87.5 \%$ and $100 \%$ of the patients have improvement of their symptoms of ocular rosacea after treatment with an initial dose of doxycycline $100 \mathrm{mg}$ daily. ${ }^{41-43}$ Still, randomized, placebo-controlled studies evaluating the efficacy of doxycycline in ocular rosacea are lacking.

\section{Doxycycline versus macrolides in the treatment of rosacea}

The first randomized, open clinical trial evaluating the efficacy macrolides versus doxycycline in the treatment of rosacea was reported in $1997 .{ }^{44}$ Patients were randomized to receive clarithromycin $250 \mathrm{mg}$ twice daily for 4 weeks, then $250 \mathrm{mg}$ once daily for four weeks $(\mathrm{n}=23)$ or doxycycline $100 \mathrm{mg}$ twice daily for 4 weeks, then $100 \mathrm{mg}$ once daily for 4 weeks $(n=17)$. After 8 weeks of treatment, there were no significant differences observed in erythema, telangiectases, or in the number of lesions between the two groups. Still, a faster decrease in lesion count was observed in the clarithromycin group, showing a statistically significant $(P<0.0005)$ difference in papules and pustules score between the two groups at weeks 4 and 6 . The authors concluded that 6 weeks of clarithomycin treatment are as effective in the treatment of rosacea as 8 weeks of doxycycline treatment.

Another randomized, open clinical trial was performed to observe if azithromycin had an equivalent or superior effect to that produced by doxycycline in the treatment of adult patients with papulopustular rosacea. ${ }^{45}$ Patients were randomized to receive azithromycin $500 \mathrm{mg} 3$ times weekly for 1 month, then $250 \mathrm{mg} 3$ times weekly for the second month, and $250 \mathrm{mg}$ twice weekly for the third month in the first group $(n=37)$. The second group received doxycycline $100 \mathrm{mg}$ once daily for 3 months $(\mathrm{n}=30)$. In both treatment groups, the mean inflammatory lesion counts were significantly decreased at the third month $(P<0.001$ in both groups), and at the second month post-treatment $(P<$ 0.001 in both groups), when compared to baseline. When the efficacies of the two treatments were compared, there were no significant differences in the percentage of decrease in lesions $(P=0.771)$ or in the patients' own assessment $(P=0.965)$. Adverse effects reported included diarrhea in four patients in the azithromycin group and epigastric burning in two patients in the doxycycline group. Only 2 patients discontinued the study because of adverse events, both of whom were in the azithromycin group. This study demonstrated that both treatments were equally effective in treating inflammatory rosacea and that intermittent azithromycin offers an alternative in the management of patients with rosacea.

\section{Doxycycline versus minocycline}

Minocycline is not approved by the FDA for the treatment of rosacea, but it is for the treatment of acne. There are currently no clinical trials that have evaluated the use of minocycline for the treatment of rosacea and due to the lack of clinical evidence comparisons of efficacy with doxycycline cannot be drawn. Minocycline has been used as a successful, longterm therapy for patients with acne vulgaris. Clinical trials of treatment of acne vulgaris with minocycline in doses of $100 \mathrm{mg}$ daily have demonstrated a statistically significant decrease in lesion count when compared with placebo. ${ }^{46}$ Still, no statistically significant differences have been demonstrated in clinical trials when comparing minocycline with doxycycline, and investigators have concluded that both are equally effective in the treatment of moderate to moderately severe acne vulgaris. ${ }^{47-49}$

An extended-release (ER) version of minocycline tablets at a dosage of $1 \mathrm{mg} / \mathrm{kg} /$ day $\left(\operatorname{Solodyn}^{\circledR}\right.$; Medicis Pharmaceutical Corporation) was approved in 2006 for the treatment of moderate-to-severe acne in patients older than $12 .{ }^{50}$ Unlike the anti-inflammatory dose of doxycycline $40 \mathrm{mg}$ for rosacea, the ER version of minocycline posses antibiotic activity.

\section{Concerns about resistance}

Conventional use of tetracycline agents in the treatment of rosacea includes doxycycline hyclate or monohydrate (100 to $200 \mathrm{mg}$ daily), minocycline hydrochloride (100 to $200 \mathrm{mg}$ daily), or tetracycline hydrochloride (500 to $1000 \mathrm{mg}$ daily). 
These dosing regimens have proven both anti-inflammatory and antibiotic activity. ${ }^{4}$ Still, concerns related to increased bacterial resistance have been raised in the last few years and several common pathogens encountered in dermatology have demonstrated bacterial resistance, including resistance to tetracyclines. ${ }^{51}$

SDD 20 mg (Periostat ${ }^{\circledR}$; CollaGenex Pharmaceuticals) is indicated for the treatment of adult periodontal disease, its mechanism having been attributed to its anticollagenase and antimatrix metalloproteinase properties. ${ }^{52,53}$ Studies have demonstrated that SDD administered twice daily for up to 18 months does not alter or promote antibiotic susceptibility patterns of normal flora or opportunistic periodontal pathogens. ${ }^{53}$ Similarly, in acne patients treated over a 6-month period with SDD $20 \mathrm{mg}$ twice daily there was no effect on Propionibacterium acnes or other cutaneous commensal bacteria. ${ }^{35}$ Also, SDD did not alter microflora composition, and did not induce the emergence of organisms resistant to doxycycline, minocycline, tetracycline, erythromycin, clindamycin, or vancomycin. ${ }^{35,54}$ Analysis of the plasma concentrations of doxycycline demonstrated that administration of $20 \mathrm{mg}$ twice daily produced maximal levels significantly lower than the minimum inhibitory concentration (MIC) required to produce an antimicrobial effect, while administration of doxycycline $50 \mathrm{mg}$ once daily has been proven to produce plasma concentrations that exceed the MIC for 2 to 3 hours. ${ }^{54}$

The lack of antibiotic resistance after treatment with anti-inflammatory dose doxycyline has also been previously demonstrated in the treatment of periodontitis. ${ }^{55}$ In a subset of subjects $(n=34)$ treated for 9 months with anti-inflammatory dose doxycycline $40 \mathrm{mg}$ once daily, microbiologic testing obtained from multiple subgingival sites demonstrated no evidence of antimicrobial selection pressure. Also, it did not alter the antibiotic susceptibility of subgingival flora and cross-resistance was not observed.

\section{Adverse effects}

The tetracycline antibiotic class has been used safely for long-term therapy in patients with rosacea and acne vulgaris. Within this antibiotic class, doxycycline is generally well tolerated. Minor side effects of tetracyclines are varied; serious side effects are rare. ${ }^{56}$ (Table 3 )

Serious drug reaction patterns to tetracycline antibiotics can be categorized as early or late. Early reactions include hypersensitivity syndrome reactions, serum-sickness-like reactions, and isolated single-organ dysfunction (involvement of one major organ: pancreatitis, hepatitis, cutaneous eruptions) which occur on average within 2 months of
Table 3 Adverse events with doxycycline (100 to $200 \mathrm{mg}$ daily)

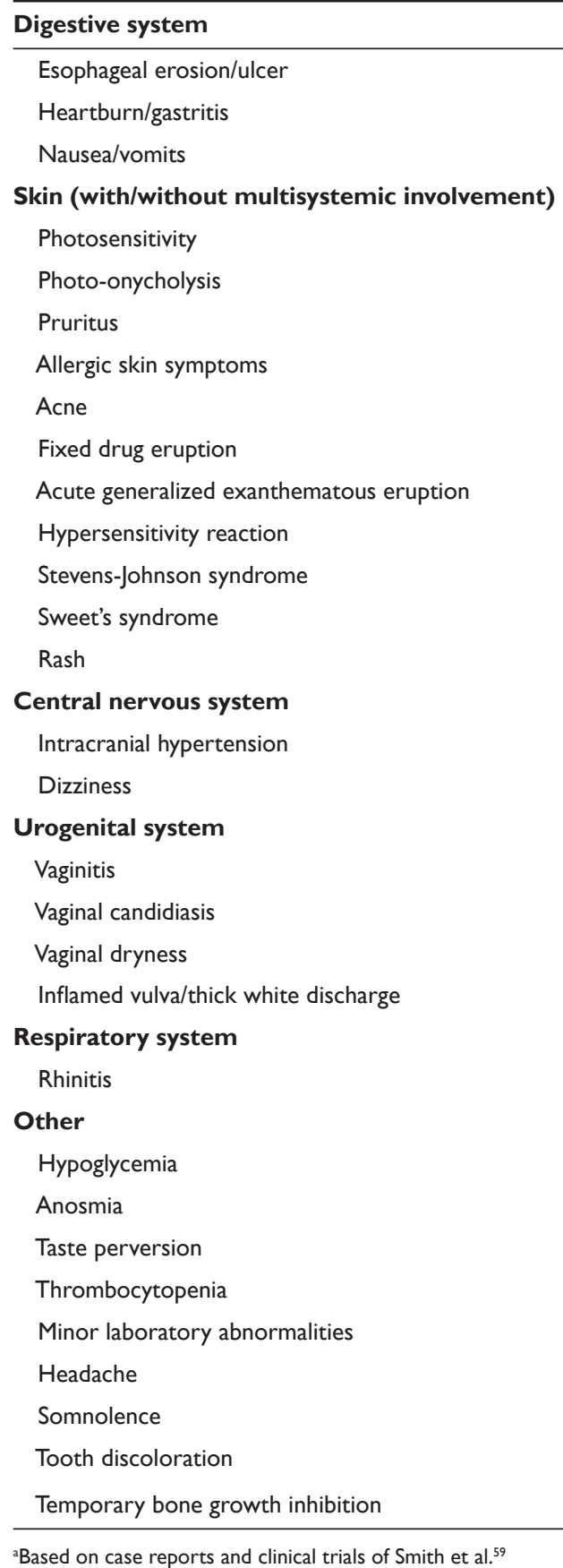

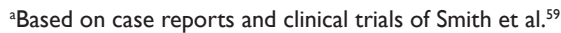

treatment. ${ }^{57,58}$ Late reactions include drug-induced lupus, which usually occurs an average of 2 years after initiation of treatment. ${ }^{58}$ Drug-induced lupus has been reported in association with minocycline and not doxycycline use.

Second-generation tetracyclines (doxycycline hyclate, doxycycline monohydrate, minocycline) offer the patient the advantage of less frequent dosing and potentially fewer side effects. ${ }^{8,56}$ Based on the number of prescriptions dispensed from January 1, 1998 to August 31, 2003, Smith et al ${ }^{59}$ estimated 
the overall incidence of adverse effects for doxycycline to be 13 per million in the United States (2.3 per million per year). A review of the literature (case reports and clinical trials) revealed that esophageal erosions and photosensitivity are the most commonly reported adverse effects of doxycycline. ${ }^{59}$

\section{Gastrointestinal adverse effects}

The modifications in structure of the second-generation tetracyclines in comparison with the first-generation tetracyclines improve their gastrointestinal absorption. This increased absorption permits lower oral doses and reduces gastrointestinal side effects. ${ }^{56}$

Doxycycline is the most common tetracycline associated with gastrointestinal upset. ${ }^{56}$ The reported rates of gastrointestinal adverse events in clinical trials for the treatment of non-rosacea conditions have been found to range from $0.54 \%$ to $51.7 \%$ for doxycycline 100 to $200 \mathrm{mg}$ daily. ${ }^{59}$

Common gastrointestinal adverse effects include heartburn, nausea, vomiting, diarrhea, gastritis, and candidiasis. ${ }^{56,59,60}$ Esophagitis and esophageal ulcerations are among the most severe gastrointestinal adverse events. They usually occur when the medication is taken before bedtime and with little or no water. ${ }^{56,60-62}$ Tetracyclines, particularly doxycycline, are the drugs implicated in most of the reported drug-induced esophageal ulcerations $(70 \%){ }^{60}$

Doxycycline hyclate has been noted to be a common cause of drug-induced esophageal ulceration. ${ }^{56,57}$ The incidence of esophageal ulcers is greater for doxycycline hyclate capsules than with tablets. The capsule may stick to the mucosa of the esophagus if taken with little water. The ulceration results from the physical contact of the capsule with the epithelial lining of the esophagus. The identification of symptoms such as odynophagia, retrosternal pain and dysphagia can be useful in the diagnosis of a doxycycline-induced esophageal ulceration. ${ }^{60,63}$ The acidity of doxycycline hyclate ( $\mathrm{pH} 2$ to 3 ) contributes to its higher risk of esophageal ulceration when compared with doxycycline monohydrate (pH 5 to 6). ${ }^{56,57,63}$ For doxycycline hyclate tablets, enteric coated delayed-release tablets (Doryx ${ }^{\circledR}$; Warner Chilcott (US) Inc.) were found to be superior to the powder-containing tablets (Vibramycin ${ }^{\circledR}$; Pfizer) when considering gastrointestinal side effects. ${ }^{56,64}$

\section{Cutaneous adverse effects}

The second most common reported adverse effect with doxycycline is skin reactions, which include photosensitivity, pruritus, and unspecified rashes. ${ }^{56,60,62,65}$ Photosensitivity and photo-onycholysis are reported in up to $7.5 \%$ of cases. ${ }^{56,57,66}$ Doses of doxycycline less than $100 \mathrm{mg}$ daily are a rare cause of photosensitivity. ${ }^{56,67}$ The relationship between the development of phototoxicity and doxycycline has been shown to be dose dependent occurring in $3 \%$ of the patients taking $100 \mathrm{mg}$ daily, $20 \%$ of the patients at $150 \mathrm{mg}$ daily and $42 \%$ at $200 \mathrm{mg}$ daily. ${ }^{67}$ Urticarial reactions may occur occasionally in doxycycline-treated patients. ${ }^{57}$ The characteristic skin pigmentation that occurs during prolonged minocycline administration is not normally seen with doxycycline. ${ }^{56}$

\section{Other less common adverse effects}

Rare side effects of doxycycline include hemolytic anemia, thrombocytopenia, eosinophilia, and neutropenia. ${ }^{56,57,68}$ Tetracyclines have the potential to cause benign intracranial hypertension (headache, photophobia, diplopia, papilledema, and dizziness, nausea/vomiting), which usually resolve after the discontinuation of the drug. ${ }^{56,69}$ A yellow-gray-brown tooth discoloration may occur in children. ${ }^{56,60,62}$ Recently a doxycycline-induced staining of teeth in an adult patient treated for acne was reported by Nelson et al. ${ }^{70}$ Tetracyclines may temporally inhibit bone growth. ${ }^{62}$ They are contraindicated in pregnancy (pregnancy category D), breast feeding women and in children younger than eight years. ${ }^{62}$ Symptoms of dizziness, vertigo or lightheadedness are rarely seen with doxycycline. ${ }^{56}$

Severe adverse effects associated with tetracyclines are rare events, nevertheless cases of doxycycline-induced Steven-Johnson syndrome and severe hypersensitivity reaction had been reported. ${ }^{71-74}$ Other uncommon reported doxycycline-induced skin eruptions include fixed drug eruption, acute generalized exanthematous pustular eruption, and Sweet's syndrome. . $^{75-77}$

\section{Safety of submicrobial dosage of doxycycline monohydrate for rosacea}

No major safety concerns have been found for the SDD. ${ }^{31,56}$ The pooled data of reported adverse events include: nasopharyngitis, diarrhea, headache, upper respiratory infections, hypertension, sinusitis, AST elevation, abdominal pain, fungal infection, and influenza. ${ }^{31,56,78}$ Gastrointestinal side effects were present but tolerable. Marked blood pressure elevation was reported but not thought to be related to the study drug. ${ }^{31,56}$ No cases of photosensitivity have been reported to date..$^{24,31,56}$ The SDD has shown a high safety profile. ${ }^{24,78}$

\section{Safety of doxycycline in comparison with minocycline and tetracycline}

Doxycycline and minocycline differ in their adverse event profile. ${ }^{59}$ Considerably fewer adverse effects have been reported for doxycycline than for minocycline; the adverse 
effects for minocycline are 5 times more common than for doxycycline. ${ }^{59}$

The case report data reviewed by Smith et $\mathrm{al}^{59}$ revealed that the predominant adverse effect secondary to doxycycline use is esophageal erosions. For minocycline a predominance of hyperpigmentation, hypersensitivity, and autoimmunerelated adverse effects was observed. Case reports do not necessarily represent the most common adverse events in the daily practice.

Based on the clinical trial data, Smith et $\mathrm{al}^{59}$ found that doxycycline-treated patients most commonly present with gastrointestinal adverse effects (gastritis, bloating, and cramps), while for minocycline-treated patients the central nervous system (dizziness) and gastrointestinal adverse effects were the most common.

In the treatment of acne, gastrointestinal adverse effects have been the most commonly reported, occurring in up to $20 \%$ of the doxycyline-treated patients and $25 \%$ of minocycline-treated patients. ${ }^{59}$ Harrison et al ${ }^{79}$ noted that the tolerance for doxycycline (50 mg daily) was similar to minocycline (50 mg daily); an excellent tolerance was found in $53 \%$ and $37 \%$ of the patients, respectively.

In a review conducted by Shapiro et $\mathrm{al}^{58}$ more reports of serious adverse events from minocycline use were observed in comparison with other tetracycline antibiotics. This may be related to the minocycline-derived reactive metabolites which are able to bind to tissue macromolecules causing direct cell damage. Minocycline metabolites may also act as haptens and may elicit immune responses such as druginduced lupus. ${ }^{58}$ To date, there are no reports of tetracyclineor doxycycline-induced lupus. Single-organ dysfunction attributable to doxycycline presents most commonly as a cutaneous adverse reactions (70\%), whereas single-organ dysfunction related to minocycline most commonly presents as pneumonitis $(45 \%){ }^{58}$

Group substitutions on the 4-ring structure of the tetracycline antibiotics account for the difference in their adverse events profile. ${ }^{56,58}$ Doxycycline has a hydroxyl side chain distinguishing it from tetracycline. ${ }^{56,58}$ Minocycline shares the basic 4-ring structure of the other tetracyclines but has a substitution of a dimethylamino group in the 7 th position ${ }^{58,80}$ (Figure 1). Neither tetracycline nor doxycycline contains this amino acid side chain which has the potential to form an iminoquinone reactive metabolite..$^{58}$

Extrapolating from the literature on aromatic anticonvulsant hypersensitivity reactions, Shapiro et al ${ }^{58}$ suggested avoiding all tetracyclines in those patients who experience a serious adverse effect while receiving doxycyxline, minocycline, or tetracycline until more information on potential crossreactivity is available.

\section{Relevant drug interactions Warfarin}

The administration of tetracyclines to patients on chronic oral anticoagulation therapy may be associated with a marked enhancement in the anticoagulant effect. ${ }^{56,8184}$ An update of the clinicallysignificant drug interactions revealed doxycycline as a "red flag" drug. Doxycycline is one of the 16 red flag drugs that account for the $80 \%$ of the clinically significant drug interactions. The interaction of doxycyline with warfarin was classified as severe and well documented. ${ }^{85}$

Penning-Van Beest et $\mathrm{al}^{84}$ found doxycycline to be the main antibiotic drug (in addition to amoxicillin) in daily practice associated with a statistically significant increase in the risk of bleeding when used concomitantly with warfarin; the relative risk, adjusted for gender and age, was 3 to 5 for doxycycline. The proportion of major bleedings attributable to the interaction of warfarin with doxycycline was estimated to be $18 \%$, gastrointestinal bleeding being the most frequent $(79 \%) .{ }^{84}$ The enhanced anticoagulation of warfarin by doxycycline administration requires a close monitoring of the patient's anticoagulation parameters. ${ }^{62}$

Pharmacodynamic as well as pharmacokinetic mechanisms are involved in the increased anticoagulant effect of warfarin when combined with doxycycline. Pharmacodynamic alteration may result from the elimination of the gut flora leading to a secondary vitamin $\mathrm{K}$ deficiency (main mechanism), or may result from the direct inhibition of the synthesis of the vitamin K-dependent coagulation factors. ${ }^{84,85}$ Pharmacokinetic interactions include the inhibition of the metabolism of warfarin, or the displacement of warfarin from plasma proteins ${ }^{84}$ Both doxycycline and warfarin are mostly protein bound, $80 \%$ to $90 \%$ and $>97 \%$ respectively. Doxycycline probably displaces the albumin-bound warfarin with a subsequent increase in its fraction. ${ }^{83}$ Interaction of doxycycline with the cytochrome P-450 system may also alter the enzyme activity, inhibiting the hepatic metabolism of warfarin and thereby leading to an elevated plasma level and an increased risk of bleeding. ${ }^{83}$

\section{Oral contraceptives}

A possible association between the use of tetracyclines and failure of oral contraceptives (OCPs) had been suggested. Still, the true incidence of those failures is unknown. ${ }^{86}$ In an analysis of unplanned pregnancies reported to the Committee on Safety of Medicines in women taking OCPs and concominant antibiotics, teracyclines, and penicillins were involved in $70 \%$ 
of the reports. ${ }^{87}$ The largest numbers of apparent reported failures occur in women using low-dose monophasic oral contraceptives containing $30 \mu \mathrm{g}$ of ethinyl estradiol. ${ }^{78,87}$

Most of the studies have not demonstrated any systematic interaction between antibiotics and OCPs. Evidence indicating that antibiotics alter blood concentrations of OCPs is lacking. Because the disposition of OCPs components is so variable among individuals, some women may be more susceptible to OCP failure. ${ }^{86}$ Modern OCP preparations contain smaller amounts of estrogen and have fewer drug interactions, which may contribute to a decrease in their efficacy when combined with doxycycline. ${ }^{86,88}$

In a controlled clinical trial, Neely et al ${ }^{89}$ evaluated the effects of doxycycline on OCPs hormone concentrations. No statistically significant differences in serum levels of ethinyl estradiol, norethindrone, or endogenous progesterone were seen between the control and treatment phases. However, a large inter-patient and intra-patient variability in ethinyl estradiol and norethindrone levels was observed. Neely et a ${ }^{89}$ suggested that pregnancies attributed to failure of OCPs because of tetracycline use could represent a true interaction that only manifests itself in a small proportion of women at risk.

Murphy et $a{ }^{90}$ found no significant decrease in the plasma ethinyl estradiol or norethindrone concentration in either short-term (24 hours) or long-term (5 to 10 days) ingestion of tetracycline (tetracycline $500 \mathrm{mg}$ orally every 6 hours) in women ingesting oral contraceptives (ethinyl estradiol $35 \mu \mathrm{g}$ and norethindrone $1 \mathrm{mg}$ ).

Archer et $\mathrm{al}^{91}$ reviewed the pharmacokinetic and the clinical literature on the efficacy of oral contraceptives when used concomitantly with antibiotic therapy. Relevant clinical reports of contraceptive failure with antibiotic use were found to be retrospective, to have multiple potential biases, and were not supported by pharmacokinetic data. Archer et a ${ }^{91}$ concluded that the available scientific and pharmacokinetic data do not support the hypothesis that antibiotics, with the exception of rifampin, lower the efficacy of oral contraceptives.

\section{Other drug interactions}

Concomitant use of tetracycline (primarily minocycline) and oral retinoids has been associated with benign intracranial hypertension. ${ }^{78}$ It is a well-documented clinically significant drug interaction, where a synergistic effect of the medications increases the risk of pseudotumor cerebri. ${ }^{85}$

Tetracyclines can interfere with methotrexate and other protein bound medications by displacing them from their binding sites. ${ }^{56}$

Anticonvulsants (barbiturates, carbamazepine, and phenitoin) induce the hepatic microsomal metabolism of tetracyclines and consequently decrease tetracycline serum concentrations. ${ }^{62}$ Cholesteramine and colestipol may bind tetracycline and reduce gastrointestinal absorption. ${ }^{62}$

\section{Dosing}

Several oral formulations of doxycycline are currently approved by the FDA (Table 3), although only doxycycline $40 \mathrm{mg}$ USP $\left(\right.$ Oracea $\left.^{\circledR}\right)$ is approved for the treatment of rosacea. Doses ranging between $40 \mathrm{mg}$ to $100 \mathrm{mg}$ daily from 8 to 16 weeks are most commonly used in the treatment of rosacea. They can be used safely in patients with renal failure. ${ }^{9,16}$

Milk, antiacids, iron supplements, and probably other substances with calcium, magnesium, aluminum, and iron have been shown to decrease tetracycline gastrointestinal absorption and should be ingested at least several hours before or after the administration of tetracyclines. ${ }^{62}$ Although doxycycline absorption may be less affected by these divalent or trivalent cations, avoiding administration within 1 to 2 hours after ingestion of interfering food or medication is prudent. ${ }^{62}$ Also, the risk of esophageal ulceration reported

Table 4 Available formulations of doxycycline ${ }^{92}$

\begin{tabular}{lllll}
\hline Active ingredient & Dosage form & Strength & Proprietary name & Generic availability \\
\hline Doxycycline & Capsule; delayed release & $40 \mathrm{mg}$ & Oracea & No \\
Doxycycline monohydrate & Capsule & $50 \mathrm{mg}, 75 \mathrm{mg}, 100 \mathrm{mg}$ & Monodox & Yes \\
Doxycycline hyclate & Capsule & $50 \mathrm{mg}, 100 \mathrm{mg}$ & Vibramycin & Yes \\
Doxycycline monohydrate & Suspension & $25 \mathrm{mg} / 5 \mathrm{~mL}$ & Vibramycin & Yes \\
Doxycycline calcium & Suspension & $50 \mathrm{mg} / 5 \mathrm{~mL}$ & Vibramycin & No \\
Doxycycline hyclate & Capsule; delayed release & $75 \mathrm{mg}, 100 \mathrm{mg}$ & N/A & Yes \\
Doxycycline hyclate & Tablet & $20 \mathrm{mg}$ & Periostat & Yes \\
Doxycycline hyclate & Tablet & $100 \mathrm{mg}$ & Vibra-tabs & Yes \\
Doxycycline hyclate & Tablet; delayed release & $75 \mathrm{mg}, 100 \mathrm{mg}, 150 \mathrm{mg}$ & Doryx & No \\
\hline
\end{tabular}


with the use of doxycycline can be minimized with adequate fluid intake and avoiding lying down after oral intake of the capsule or tablet. ${ }^{63}$ For this reason, doxycycline is best administered in the morning with plenty of water. Doses of doxycycline $<100 \mathrm{mg}$ daily are seldom associated with photosensitivity and have not been reported to date with the use of SDD. ${ }^{24,56,57}$ Still, patients should be warned about this potential side effect and advised to practice sun protection measures.

\section{Conclusions}

Available research and clinical experience have demonstrated that doxycycline safely improves the signs and symptoms of rosacea. Doxycycline exhibits antiangiogenic and anti-inflammatory properties that are effective in the treatment of rosacea and penetrates into normal and inflammatory tissues more readily than tetracycline. Also, it exhibits superior pharmacokinetic properties and lesser toxicity when compared with first-generation tetracyclines. Subantimicrobial dose doxycycline has not been associated with the development of antibiotic resistance. Anti-inflammatory dose doxycycline $40 \mathrm{mg}$ is dosed once daily improving patient compliance without altering antibiotic susceptibility, and having lesser toxicity when compared to the standard $100 \mathrm{mg}$ daily dose. In sum, a series of clinical studies have confirmed that doxycycline is safe and effective as a therapeutic option in rosacea.

\section{Disclosures}

The authors have no conflicts of interest to disclose.

\section{References}

1. Berg M, Liden S. An epidemiological study of rosacea. Acta Derm Venerol. 1989;69:419-423.

2. Powell FC. Rosacea. N Engl J Med. 2005;352:793-803.

3. Wilkin J, Dahl M, Detmar M, et al. Standard classification of rosacea: report of the National Rosacea Society Expert Committee on the Classification and Staging of Rosacea. J Am Acad Dermatol. 2002;46:584-587.

4. Pelle MT, Crawford GH, James WD. Rosacea: II. Therapy. J Am Acad Dermatol. 2004;51:499-512.

5. Sneddon IB. A clinical trial of tetracycline in rosacea. Br J Dermatol. 1966;78:649-652.

6. Smilack JD. The tetracyclines. Mayo Clin Proc. 1999;74:727-729.

7. Sapadin AN, Fleischmajer R. Tetracyclines: Nonantibiotic properties and their clinical implications. J Am Acad Dermatol. 2006;54(2):258-265.

8. Maibach H. Second-generation tetracyclines, a dermatologic overview: Clinical uses and pharmacology. Cutis. 1991;48:411-417.

9. Cunha BA, Sibley CM, Ristuccia AM. Review doxycycline. Ther Drug Monit. 1982;4:115-135.

10. Jonas M, Cunha BA. Review minocycline. Ther Drug Monit. 1982;4 137-145.

11. Macdonald H, Kelly RG, Allen ES. Pharmacokinetic studies of minocycline in man. Clin Pharmacol Ther. 1973;14:852.

12. Saivin S, Houin G. Clinical pharmacokinetics of doxycycline and minocycline. Clinical Pharmacokinet. 1988;15:355-366.
13. Fabre J, Milek E, Kalfopoulos P, et al. The kinetics of tetracyclines in man. Digestive absorption and serum concentrations. Schweiz Med Wochenschr. 1971;101:593-598.

14. Weinberg JM. The anti-inflammatory effects of tetracyclines. Cutis. 2005;75 Suppl 4:S6-S11.

15. Cullen S, Crounse R. Cutaneous pharmacology of the tetracyclines. J Invest Dermatol. 1965;45:263-268.

16. Pallett AP, Smyth EG. Clinician's guide to antibiotics. Tetracycline. Br J Hosp Med. 1988;40:385-390.

17. Webster G, Del Rosso JQ. Antiinflammatory effects of Tetracyclines. Dermatology Clin. 2007;25:133-135.

18. Esterly NB, Furey NL, Flannagan LE. The effect of antimicrobial agents on chemotaxis. J Invest Dermatol. 1978;70:51-55.

19. Esterly NB, Kovansky JS, Furey NS. Neutrophil chemotaxis in patients with acne receiving tetracyclines. Arch Dermatol. 1984;120: 1308-1313.

20. Gabler WL, Creamer HR. Supression of human neutrophil functions by tetracycline. J Periodontal Res. 1991;26:52-58.

21. Thong YH, Ferrante A. Inhibition of mitogen-induced human lymphocyte proliferative responses by tetracycline analogs. Clin Exp Immunol. 1979;35:443-446.

22. Pruzanski W, Greenwald RA, Street IP, Laliberte F, Stefanski E, Vadas P. Inhibition of enzymatic activity of phospholipase A2 by minocycline and doxycycline. Biochem Pharmacol. 1992;P44:1165-1170.

23. Wise RD. Submicrobial doxycycline and rosacea. Comp Ther. 2007;33:78-81.

24. Bikowski JB. Subantimicrobial dose doxycycline for acne and rosacea. Skinmed. 2003;2:234-245.

25. Golub LM, Lee HM, Ryan ME, Giannobile WV, Payne J, Sorsa T. Tetracyclines inhibit connective tissue breakdown by multiple nonantimicrobial mechanisms. Adv Dent Res. 1998;12:12-26.

26. Golub LM, Lee HM, Lehrer G, et al. Minocycline reduces gingival collagenolytic activity during diabetes: preliminary observations and a proposed new mechanism of action. J Periodont Res. 1983;18: 516-526.

27. Golub LM, Ramamurthy NS, McNamara TF, Greenwald RA, Rifkin BR. Tetracyclines inhibit connective tissue breakdown: new therapeutic implications for an old family of drugs. Crit Rev Oral Biol Med. 1991;2:297-321.

28. Berman B, Zell D. Subantimicrobial dose doxycycline: a unique treatment for rosacea. Cutis. 2005;75 Suppl 4:S19-S24.

29. Bikowski J. New approaches to rosacea therapy. Skin Aging. 2005;13 Suppl 2:S13-S15.

30. Hanemaaijer R, Visser H, Koolwijk P, et al. Inhibition of MMP synthesis by doxycycline and chemically modified tetracyclines (CMTs) in human endothelial cells. Adv Dent Res. 1998;12:114-118.

31. Del Rosso JQ, Webster GF, Jackson M, et al. Two randomized phase III clinical trials evaluating anti-inflammatory dose doxycycline (40-mg doxycycline, USP capsules) administered once daily for treatment of rosacea. J Am Acad Dermatol. 2007;56:791-802.

32. Webster GF, Toso SM, Hegemann L. Inhibition of a model of in vitro granuloma formation by tetracyclines and ciprofloxacin. Involvement of protein kinase C. Arch Dermatol. 1994;130:748-752.

33. Amin AR, Attur MG, Thakker GD, et al. A novel mechanism of action of tetracyclines: effects on nitric oxide synthases. Proc Natl Acad of Sci U S A. 1996;93:14014-14019.

34. Amin AR, Patel RN, Thakker GD, Lowenstein CJ, Attur MG, Abramson SB. Post-transcriptional regulation of inducible nitric oxide synthase mRNA in murine macrophages by doxycycline and chemically modified tetracyclines. FEBS Lett. 1997;410:259-264.

35. Skidmore R, Kovach R, Walker C, et al. Effects of subantimicrobialdose doxycycline in the treatment of moderate acne. Arch Dermatol. 2003;139 (4):459-464.

36. Thiboutot D. Efficacy and safety of subantmicrobial-dose doxycycline for the treatment of rosacea [poster]. 63rd Annual Meeting of the American Academy of Dermatology; February 18-22, 2005; New Orleans, LA. P128. 
37. Sanchez J, Somolinos AL, Almodovar PI, Webster G, Bradshaw M, Powala C. A randomized, double-blinded, placebo-controlled trial of the combined effect of doxycycline hyclate 20 -mg tablets and metronidazole $0.75 \%$ topical lotion in the treatment of rosacea. $J$ Am Acad Dermatol. 2005;53:791-797.

38. Fowler JF. Combined effect of anti-inflammatory dose doxycycline (40-mg doxycycline, USP monohydrate controlled-release capsules) and metronidazole topical gel $1 \%$ in the treatment of rosacea. J Drugs Dermatol. 2007;6:641-645.

39. Del Rosso J, Schlessinger J, Werschler P. Comparison of anti-inflammatory dose doxycycline versus doxycycline $100 \mathrm{mg}$ in the treatment of rosacea. J Drugs Dermatol. 2008;7:573-576.

40. Akpek EK, Merchant A, Pinar V, Foster CS. Ocular rosacea: Patient characteristics and follow-up. Ophthalmology. 1997;104:1863-1867.

41. Frucht-Pery J, Chayet AS, Felman ST, Lin S, Brown SI. The effect of doxycycline in ocular rosacea. Am J Ophthalmol. 1989;107:434-435.

42. Frucht-Pery J, Sagi E, Hemo I, Ever-Hadani P. Efficacy of doxycycline and tetracycline in ocular rosacea. Am J Ophthalmol. 1993;116:88-92.

43. Quaterman MJ, Johnson DW, Abele DC, Lesher JL, Hull DS, Davis LS. Ocular rosacea: Signs, symptoms, and tear studies before and after treatment with doxycycline. Arch Dermatol. 1997;133:49-54.

44. Torresani C, Pavesi A, Manara GC. Clarithromycin versus doxycycline in the treatment of rosácea. Int J Dermatol. 1997;36:938-946.

45. Akhyani M, Ehsani AH, Ghiasi M, Jafari AK. Comparison of efficacy of azithromycin vs. doxycycline in the treatment of rosacea: a randomized open clinical trial. Int J Dermatol. 2008;47:284-288.

46. Hersle K, Gisslen H. Minocycline in acne vulgaris: a double-blind study. Curr Ther Res. 1976;19:339-342.

47. Harrison PV. A comparison of doxycycline and minocycline in the treatment of acne vulgaris. Clin Exp Dermatol. 1988;13:242-244.

48. Laux B. Treatment of acne vulgaris. A comparison of doxycycline versus minocycline. Dermatologist. 1989;40:577-581.

49. Olafsson JH, Gudgierson J, Eggertsdottir GE, Kristjansson F. Doxycycline versus minocycline in the treatment of acne vulgaris: a doubleblind study. J Dermatol Treat. 1989;1:15-17.

50. Del Rosso JQ. Recently approved systemic therapies for acne vulgaris and rosacea. Cutis. 2007;80:113-120.

51. Eady AH, Cove JH, Layton AM. Is antibiotic resitance in cutaneous propionibacteria clinically relevant? Implications of resistance for acne patients and prescribers. Am J Clin Dermatol. 2003;4:813-831.

52. Thomas J, Walker C, Bradshaw M. Long-term use of subantimicrobial dose doxycycline does not lead to changes in antimicrobial susceptibility. J Perio. 2000;71:1472-1483.

53. Golub LM, Sorsa T, Lee HM, et al. Doxycycline inhibits neutrophil (PMN)-type matrix metalloproteinases in human adult periodontitis gingiva. J Clin Periodontol. 1995;22:100-109.

54. Del Rosso JQ. A status report on the use of subantimicrobial-dose doxycycline: A review of the biologic and antimicrobial effects of the tetracyclines. Cutis. 2004;74:118-122.

55. Walker C, Webster GF, Del Rosso JQ. A muticenter, double-blind, randomized trial to evaluate the long-term anti-inflammatory doxycycline (40 mg) therapy: results of the lack of effect on bacterial flora [poster]. Foundation for Reaserch and Education in Dermatology, Fall Clinical Dermatology Conference, October 6-9, 2006; Las Vegas, Nevada.

56. Sloan B, Scheinfeld N. The use and safety of doxycycline hyclate and other second-generation tetracyclines. Expert Opin Drug Saf. 2008;7:571-577.

57. Del Rosso JQ. Systemic therapy for rosacea: focus on oral antibiotic therapy and safety. Cutis. 2000;66:7-13.

58. Shapiro LE, Knowles SR, Shear NH. Comparative safety of tetracycline, minocycline, and doxycycline. Arch Dermatol. 1997;133:1224-1230.

59. Smith K, Leyden JJ. Safety of doxycycline and mnocycline: a systematic review. Clin Ther. 2005;27:1329-1342.

60. Segelnick SL, Weinberg MA. Recognizing doxycycline-induced esophageal ulcers in dental practice: a case report and review. $J \mathrm{Am}$ Dent Assoc. 2008;139:581-585.

61. Biller JA, Flores A, Buie T, Mazor S, Katz AJ. Tetracycline-induced esophagitis in adolescent patients. J Pediatr. 1992;120:144-145.
62. Smilack JD. The tetracyclines. Mayo Clin Proc. 1999;74:727-729.

63. Lanza FL. Esophageal ulceration produced by doxycycline Review of the literature and comparison of the injury from doxycycline hyclate and hydrochloride with that from doxycycline monohydrate. Curr Ther Res Clin Exp. 1988;44:475-484.

64. Berger RS. A double-blind, multiple-dose, placebo-controlled, crossover study to compare the incidence of gastrointestinal complaints in healthy subjects given Doryx R and Vibramycin R. J Clin Pharmacol. 1988;28:367-370.

65. Smith K, Leyden JJ. Safety of doxycycline and minocycline: a systematic review. Clin Ther. 2005;27:1329-1342.

66. Carroll LA, Laumann AE. Doxycycline-induced photo-onycholysis. J Drugs Dermatol. 2003;2:662-663.

67. Layton AM, Cunliffe WJ. Phototoxic eruptions due to doxycycline-a dose-related phenomenon. Clin Exp Dermatol. 1993;18:425-427.

68. Simpson MB, Pryzbylik J, Innis B, Denham MA. Hemolytic anemia after tetracycline therapy. N Engl J Med. 1985;312:840-842.

69. Pierog SH, Al-Salihi FL, Cinotti D. Pseudotumor cerebri - a complication of tetracycline treatment of acne. J Adolesc Health Care. 1986;7:139-140.

70. Nelson R, Parker SR. Doxycycline-induced staining of adult teeth: the first reported case. Arch Dermatol. 2006;142:1081-1082.

71. Cac NN, Messingham MJ, Sniezek PJ, Walling HW. Stevens-Johnson syndrome induced by doxycycline. Cutis. 2007;79:119-122.

72. Curley RK, Verbow JL. Stevens-Johnson syndrome due to tetracyclinea case report (doxycycline) and a review of the literature. Clin Exp Dermatol. 1987;12:124-125.

73. Gallais V, Randrianjohanny A, Robineau M, Laroche L. Stevens-Johnson syndrome caused by doxycycline. Presse Med. 1997;26:855.

74. Robles DT, Leonard JL, Compton N, et al. Severe drug hypersensitivity reaction in a young woman treated with doxycycline. Dermatology. 2008;217:23-26

75. Gul U, Gonul M, Soylu S, Kaya I. Doxycycline-induced fixed drug eruption. J Dermatolog Treat. 2008;19:126-127.

76. Trüeb RM, Burg G. Acute generalized exanthematous pustulosis due to doxycycline. Dermatology. 1993;186:75-78.

77. Khan Durani B, Jappe U. Drug-induced Sweet's syndrome in acne caused by different tetracyclines: case report and review of the literature. Br J Dermatol. 2002;147:558-562.

78. Berman B, Perez OA, Zell D. Update on rosacea and anti-inflammatorydose doxycycline. Drugs Today. 2007;43:27-34.

79. Harrison PV. A comparison of doxycycline and minocycline in the treatment of acne vulgaris. Clin Exp Dermatol. 1988;13:242-244.

80. Allen JC. Minocycline. Ann Intern Med. 1976;85:482-487.

81. Baciewicz AM, Bal BS. Bleeding associated with doxycycline and warfarin treatment. Arch Intern Med. 2001;161:1231.

82. Caraco Y, Rubinow A. Enhanced anticoagulant effect of coumarin derivatives induced by doxycycline coadministration. Ann Pharmacother. 1992;26:1084-1086.

83. Hasan SA. Interaction of doxycycline and warfarin: an enhanced anticoagulant effect. Cornea. 2007;26:742-743.

84. Penning-van Beest FJ, Koerselman J, Herings RM. Risk of major bleeding during concomitant use of antibiotic drugs and coumarin anticoagulants. J Thromb Haemost. 2008;6:284-290.

85. Barranco VP. Update on clinically significant drug interactions in dermatology. J Am Acad Dermatol. 2006;54:676-684.

86. Dickinson BD, Altman RD, Nielsen NH, Sterling ML; Council on Scientific Affairs, American Medical Association. Drug interactions between oral contraceptives and antibiotics. Obstet Gynecol. 2001;98:853-860.

87. Back DJ, Grimmer SF, Orme ML, Proudlove C, Mann RD, Breckenridge AM. Evaluation of Committee on Safety of Medicines yellow card reports on oral contraceptive-drug interactions with anticonvulsants and antibiotics. Br J Clin Pharmacol. 1988;25:527-532.

88. Szoka PR, Edgren RA. Drug interactions with oral contraceptives: compilation and analysis of an adverse experience report database. Fertil Steril. 1988;49:31S-38S. 
89. Neely JL, Abate M, Swinker M, D’Angio R. The effect of doxycycline on serum levels of ethinyl estradiol, norethindrone, and endogenous progesterone. Obstet Gynecol. 1991;77:416-420.

90. Murphy AA, Zacur HA, Charache P, Burkman RT. The effect of tetracycline on levels of oral contraceptives. Am J Obstet Gynecol. $1991 ; 164: 28-33$.
91. Archer JS, Archer DF. Oral contraceptive efficacy and antibiotic interaction: a myth debunked. J Am Acad Dermatol. 2002;46:917-923.

92. FDA.gov (homepage on the Internet). Approved Drug Products with Therapeutic Equivalence Evaluations (Orange Book). (updated 2009 Jan 23; cited 2009 Feb 26) Available from: http://www.fda.gov/cder/ orange/default.htm.

\section{Publish your work in this journal}

Clinical, Cosmetic and Investigational Dermatology is an international, peer-reviewed, open access, online journal that focuses on the latest clinical and experimental research in all aspects of skin disease and cosmetic interventions. All areas of dermatology will be covered; contributions will be welcomed from all clinicians and basic science researchers globally. This journal is indexed on CAS.

The manuscript management system is completely online and includes a very quick and fair peer-review system, which is all easy to use. Visit http://www.dovepress.com/testimonials.php to read real quotes from published authors.

Submit your manuscript here: http://www.dovepress.com/clinical-cosmetic-and-investigational-dermatology-journal 